\title{
Managing human disturbance of wildlife in coastal areas
}

Running title: Managing human disturbance of coastal wildlife

\begin{abstract}
.
Human disturbance of wildlife is an under recognised and under regulated problem. This article discusses traditional approaches to conservation management in protecting wildlife from disturbance, in the context of the New Zealand coastal environment and threatened birds. Limitations and challenges are identified, and alternative actions proposed. The key problems are deficiencies in regulation of species disturbance, lack of definition of thresholds of harm which contemplate rarity and conservation status, insufficient comprehensive wildlife conservation planning and the need for innovative planning methods which address species mobility, permeable boundaries and environmental dynamism. Regulatory controls including enforcing setbacks/approach distances through either extended species protection or "mobile habitat" protection are recommended.
\end{abstract}

Keywords: wildlife, disturbance effects, biodiversity protection, Wildlife Act 1953, Resource Management Act 1991 


\section{Introduction}

Disturbance is the behavioural or physiological response of an animal to the presence of stimuli, such as a potential predator, or an anthropogenic source, such as people or vehicles. (Weston et al. 2012, 269, Van Der Zande and Verstrael 1985, 90, Fox and Madsen 1997, 1, Glover et al. 2011, 327). Anthropogenic causes are the form most commonly studied (Weston et al. 2012, 269) and are the focus of this discussion. Arising in a variety of forms, disturbance has been identified as limiting populations and species (Martin et al. 2015, 73, Glover et al. 2011, 326, Koch and Paton 2014, 58, Whitfield and Rae 2014, 57). Less evident than direct species take, disturbance is a more cryptic and insidious form of damage. Harm to species caused by disturbance may be dislocated in space and/or time from the source of the damage, and may be attributable to a range of causes (Weston et al. 2012, 269).

For the law and related mechanisms reliant on causation, intention, proof and enforcement this presents problems. These problems are reflected in conservation planning regimes, particularly where threatened species exist outside of protected areas. This article discusses the meaning of disturbance in its general application, and the limits of species protection from disturbance in New Zealand. It contrasts this with the European position, and then moves on to consider the limits of habitat protection and planning in managing species disturbance. The article uses the example of the New Zealand coastal environment, coastal birds, and a case study of the New Zealand dotterel to draw out particular limitations.

Adverse effects of disturbance include changes in distribution (eg short term movement or displacement), behaviour (eg flight response or increased vigilance), demography (eg reduced fecundity/survival) and changes in population size (Gill 2007, 10). In New Zealand, long thin coastal margins with permeable boundaries present particularly challenging conditions for managing the impact of people upon threatened and at risk species. For many coastal birds in New Zealand and elsewhere, disturbance is rising (Schlacher, Neilson et al. 2013, Weston et al. 2012, 269, Lord et al. 1997, 18, Lord et al. 2001, 
237 , Woodley 2012,233 ) in tandem with rapidly intensifying use and development of coastal space (Makgill and Rennie 2012, 138).New Zealand, despite its comparatively low human population, has an accentuated species loss profile due to unique biogeographical conditions matched with high numbers of endemic species. Coastal birds have the greatest proportion of threatened species within their ranks (Hitchmough 2013).

Although disturbance is established as a key stress, particularly to shorebirds, evidence is lacking as to when, and at what levels, it becomes adverse. Furthermore, making a link to a bird's behavioural or physiological response and an impact at population level is not well researched and establishing and managing disturbance is made more complex by the species-specific nature of the stress (Liley and Sutherland 2007, 82, Blumstein et al. 2003, 99, Navedo and Herrera 2012, 373, Glover et al. 2011, 326). Disturbance can have a major impact on a bird's population size and breeding birds tend not to use highly disturbed sites (Liley 2007, Schlacher, Neilson et al. 2013). Human activity is not alone in causing stress, as disturbance may also arise from associated human use of vehicles, boats, aeroplanes and other machinery, and domestic animals (Tarr 2010). A recent Australian study concluded that vehicles driven on sandy shores frequently and intensely disturb birds on open-coast beaches (Weston et al. 2014, 999). Yet the activity does not necessarily need to be big, loud and noisy as plentiful evidence exists that simple recreational pastimes such as walking, particularly if accompanied by a dog, can considerably disturb coastal species dependent upon species type, place, time and proximity (Schlacher, Neilson et al. 2013, Lord 2001, 237).

\section{Management challenges}

This poses a problem for coastal management, particularly of threatened species, as active recreational pursuits, commonly in tandem with tourism, are widely supported and encouraged due to social, cultural and economic benefits (Maguire et al. 2011, 781). In the context of coastal New Zealand, public access to the coast is firmly engrained in the public psyche and protected as a matter of national importance under $s 6(d)$ of the Resource Management Act 1991 (RMA). Tourism and recreation are intensifying in the coastal marine area, and new active and mechanised modes of recreation are augmenting traditional 
pursuits such as walking and fishing (New Zealand Coastal Policy Statement 2010 (NZCPS) Preamble, Collins 2013, Taylor et al. 2013, 23, Schlacher, Neilson et al. 2013, Davenport 2006, Defeo et al 2009, 3). As well as furnishing "social goods" these activities are typically viewed asenvironmentally benign, in contrast to activities of a more permanent and industrial nature such as sand dredging or erection of structures. Social and cultural conditions enabling widespread human use of the coastal environment present a challenge to managing disturbance. Management challenges are intensified by the characteristics of disturbance, the manifestation of harm, and the state of knowledge limitations previously mentioned. A final and important factor complicating effective management is the natural environment itself, and aspects such as dynamism, species mobility and distribution, and topography.

\section{Approaches to management}

Traditional approaches to conserving species and habitat include species protection which regulates the taking or harming of wildlife, the protection of wildlife habitat, and more recently planning schemes designed to rationally organise and regulate human activity in the environment. Although disturbance may be addressed by each of these means, challenges arise which merit further consideration.

\section{Species Protection}

Law regulating the hunting and killing of animals may also contemplate related forms of harm to animals including disturbance. However, the law tends to be limited to intentional acts or those occurring within protective reserves. In New Zealand the primary law for wildlife protection is the Wildlife Act 1953, the key provision of which is s 63(1)(a) which prohibits hunting or killing of protected wildlife without lawful authority. Section 2 of the Wildlife Act 1953 defines the phrase 'hunt or kill' to include the hunting, killing, taking, trapping, or capturing of any wildlife by any means. Judicial interpretation has included incidental loss, where it is known that actions may interfere with the natural and ordinary activities of the wildlife and may harm the wildlife (Solid Energy New Zealand Ltd v Minister of Energy [2009] NZRMA [86]). 
Pursuing, disturbing, or molesting wildlife are also forbidden under the $\mathrm{s} 2$ definition of "hunt or kill". Inclusion of these terms potentially widens the breadth of protection and moves from considerations of mortality to definition of harm. However, the scope of disturbance has been read down by judicial interpretation to not include unintentional disturbance, such as when wildlife is startled without a person taking direct action in relation to it. The justification for this is that "Once disturbed in this incidental way it remains free to return to its original place or not as it chooses"(Solid Energy New Zealand Ltd v Minister of Energy [2009] NZRMA [86]). Similar reasoning was also applied to watching and following an animal in its natural state.

This finding sensibly limits the reach of s 63(1) in order to avoid interpretations where protective responses may not be necessary and could create absurdity. It fails to recognise, however, that there may be situations where disturbance in an incidental manner causes harm to species, and may require regulation. The potential for damage of this kind is recognised only in the context of "wildlife refuges" constituted under the s 14(3) Wildlife Act 1953 , whereby an offence of disturbance can be created independently of hunting and killing and introducing a broader range of human actions inducing a disturbance response. As might be expected birds therefore receive greater protection from disturbance in "wildlife refuges", however, a key limitation to this provision is the restriction of refuges to less than one $\%$ of the public conservation estate (Controllerand Auditor General 2006, 17).

Outside of wildlife refuges, regulation of disturbance will therefore turn upon human intention as opposed to level of harm, and conditioned by an assumption that disturbance through temporary displacement is not harmful. A second assumption is that care is only required within limited wildlife refuges, and birds outside of these, regardless of threat status, do not warrant protection from disturbance unless in the context of "hunting and killing". As a result, any species protection from disturbance under the Wildlife Act 1953 is significantly reduced by absence of intention, level of harm, and place, thus limiting protection of threatened species in the generalenvironment (non-protected areas). As an example, current interpretation would appear to exclude human recreation in coastal spaces which impacts 
nesting and foraging birds through temporary displacement. Given that disturbance is on the rise, and noting the prevalence of threatened coastal species in New Zealand, this article argues that the law requires revision to close the gap between the concerns of science and the protection provided by regulatory mechanisms.

These matters have been the subject of consideration in the United Kingdom in the context of European Union law. A requirement for intention for an offence of disturbance of species is mirrored in the European Habitats Directive 92/43/EEC and Birds Directive 2009/147/EC. In relation to European Protected Species, Article 12(1)(b) of the Habitats Directive provides that protection from, amongst other things protection of listed species from "deliberate disturbance of these species, particularly during the period of breeding, rearing, hibernation and migration". Article 5(d) of the Birds Directive takes a similar position, but introduces a focus upon level of harm through prohibiting disturbance that is "significant" as concerns the objectives of the Directive.

Article 12(1)(b) of the Habitats Directive was considered by the United Kingdom Supreme Court in Vivienne Morge v Hampshire County Council [2011] UKSC 2 in the context of an appeal against planning permission for a proposed busway, challenged on environmental grounds due to potential impact upon protected bat species. At issue, was the meaning of deliberate disturbance and the threshold or level of disturbance required to fall within the prohibition. Commission guidance (Environment Directorate General of the European Commission 2007) on Article 12(1)(b) describe deliberate actions as:

"'Deliberate' actions are to be understood as actions by a person who knows, in light of the relevant legislation that applies to the species involved, and the general information delivered to the public, that his action will most likely lead to an offence against the species, but intends this offence or, if not, consciously accepts the foreseeable results of his action."

The guidance suggests intention is formed through the legislation together with provision of general information to the public. This anticipates knowledge of the species' presence in the 
vicinity and the provision of advice that disturbance may ensue in particular circumstances. Lord Brown in Vivienne Morge v Hampshire County Councilrestated the position as:

Put more simply, a deliberate disturbance is an intentional act knowing that it will or may have a particular consequence, namely disturbance of the relevant protected species. The critical, and altogether more difficult, question is what precisely in this context is meant by "disturbance".

The focus therefore turned to determining the level of disturbance required to fall within the prohibition. At issue was the 2010 decision of the Court of Appeal that the construction of disturbance under Article 12(1)(b) required that disturbance must have a detrimental impact so as to affect the conservation status of the species at population level. Both Courts in forming their conclusions on this matter had regard to the Commission Guidance which amongst other things noted a requirement for a species-by species approach which examined the intensity, duration and frequency of repetition of disturbances, direct and indirect negative effects, particular sensitivities of species including important life cycle stages, and of the effect on the conservation status of the species at population level and biogeographic level in a member state.

In overturning the decision of the Court of Appeal on the level of disturbance required, the Supreme Court decided that there was no requirement to prove a detrimental impact so as to affect the conservation status of the species at population level, rather each case should be decided upon its merits with competent authorities reflecting carefully on the level of disturbance considered harmful taking into account the specific characteristics of the species. In addition, and in confirmation of the Guidance document, the Supreme Court added two further matters for consideration in determining the requisite level of disturbance. These were the rarity and conservation status of the species in question and the impact of the disturbance on the local population of a particular protected species. Under the Birds Directive the introduction of the qualifier "significant" to disturbance invokes similar considerations, yet with a higher threshold and with particular concern for sensitive life cycle stages such as breeding, rearing, hibernation and migration. 
The provisions of the Directives afford species protection that is in addition to habitat protection. Unlike the fixed shield of a protected area, species protection is a defence which travels with the animal. The reach of this protection in the general environment is an important consideration. Human activity disturbs species in many ways and to what extent are "normal" activities such as farming or recreation captured by prohibitions upon disturbance? And at what point should a "normal" activity be proscribed? These are important consideration in relation to policy and regulatory controls, and are of particular relevance to considering how to plan and manage New Zealand coastal areas where threatened species are prevalent.

Article 9 of the Birds Directive enables derogations to permit activity which contravenes the prohibitions, where satisfactory solutions do not exist, for reasons including the interests of public health and safety and to prevent serious damage to crops, livestock, forests, fisheries and water. Article 16 of the Habitats Directive creates further extensive exceptions by enabling derogation for reasons including: " $(c)$ in the interests of public health and public safety, or for other imperative reasons of overriding public interest, including those of a social or economicnature and beneficial consequences of primary importance for the environment". However, such derogations require precise indication of the damage to the environment permitted and stated with sufficient specificity as to intention (Commission of the European Communities v Federal Republic of Germany Case 412/85 [1987] ECR 3503).

In summary, the European position affords stronger protection than in New Zealand as deliberate disturbance of protected species is explicitly prohibited independent of "hunting or killing", whereas in New Zealand it is not. In addition, when assessing the level of prohibited disturbance, threat status of the species is contemplated, with rarity gaining greater import in relation to disturbance, and impacting the likelihood of prohibition in that disturbance to species that are declining in numbers is likely to be considered more harmful to species that are increasing in number. Furthermore, the United Kingdom position can be differentiated by a direct feed of the Habitats Directive into planning decisions by virtue of the regulations which govern domestic effect of the Directive. This position gives negative 
impacts caused by disturbance higher visibility than in the New Zealand context, where offences under the Wildlife Act 1953 are not integrated with resource management planning under the Resource Management Act 1991. The New Zealand position is characterised by a reactive case by case approach with the offence/and or problem of disturbance not being visibly tethered to alternative and more proactive implementation measures.

Additional limiting factors arise concerning prohibition of deliberate disturbance. The current state of knowledge is an impediment. Decisions from New Zealand courts reveal substantially incomplete evidential foundations as to the presence and distribution of species and the nature and effect of a range of impacts to species (Wallace 2014, 386). Furthermore, in New Zealand, implementation of the Wildlife Act 1953 is inadequate (Wallace and Fluker 2016 in press). For threatened species in New Zealand, species protection from disturbance under the Wildlife Act 1953 is thus constrained through a requirement for intent to disturb, lack of clarity as to the meaning of disturbance including judicial interpretation limiting consideration of temporary displacement of wildlife, lack of integration between wildlife offences and planning mechanisms, and lack of knowledge and implementation deficits.

\section{Habitat protection and the potential for "mobile" protection}

\section{Limitations of fixed reserves}

Habitat protection may supplement species protection from disturbance by definition of protected area and regulation of activities which create disturbance. The prime limitation of the approach is the fixed nature of the protection which may fail to recognise animal mobility in the environment and fail to take account of important connections such as associations with other areas as foraging grounds, breeding sites or water sources. The complexity of the coastal environment including its dynamism (Makgill and Rennie 2012, 139) may also confound static protection. Furthermore, protective reserves may prove insufficient in terms of extent and representativeness, a problem evident in the New Zealand environment, with particular reference to coastal habitat (Ministry for the Environment 2007, 3, Craig et al.2000, 66). 
Classification of reserve status will have a significant bearing on constraining human disturbance of species as does reserve design. A protected area management category such as a Strict Nature Reserve classification (IUCN 1a) affords the most stringent protection and strictly controls human visitation, use and impacts (Lausche and Burhenne-Guilmin 2011, 27). In New Zealand more stringent protection is gained through wildlife refuges under the Wildlife Act 1953, nature reserves under the Reserves Act 1977 or as wilderness areas under the Conservation Act 1987, the Reserves Act 1977 and the National Parks Act 1981. Apart from the impact of protected offshore islands, contribution to protection of coastal areas by this more stringent protection is limited (Department of Conservation 2011). Reliance upon offshore islands to produce conservation gains has been a very effective strategy applied in New Zealand to enable bird populations to recover from the significant depredation caused by invasive alien species pervasive on the Mainland and also from habitat loss, modification and disturbance (Wilson 2004, 263). Ringed off from these elements and comprising entire ecosystems and sequences, species and populations have flourished. Replication of these conditions on long thin coastal strips, fringed by urban, agricultural and industrial activities is significantly challenging, even for areas identified as internationally significant under the Ramsar Convention (Wallace 2015). Regional coastal plans/and or coastal environment plans under the RMA, and conservation management strategies under the Conservation Act 1987, may recognise human disturbance of species as an ongoing adverse effect in the coastal marine area, but this article recommends further active measures to limit the damage as discussed below.

The example of the Northern New Zealand dotterel, demonstrates challenges in delivering habitat protection limiting disturbance in the New Zealand coastal environment. Tuturiwhatu, the endemic New Zealand dotterel, has population of approximately 2175 individuals (Dowding 2013). The bird's range has contracted significantly and a nationwide census indicates distribution that is "widely and thinly spread around the coast of the North Island, mainly north of a line between Taranaki and northern Hawke's Bay". (Dowding and Moore, 31). At a national level dotterel has been listed Threat Classification 
Nationally Vulnerable, Criterion (B1/1) Qualifier (CD) Conservation Dependent (Miskelly et al. $2008,128)$.

Ground nesting habits on open sandy spits or beaches, frequented by people and introduced animals, immediately reveal the vulnerability of this species (Dowding and Davis $2007,1)$. Dotterel chicks are precocial (independent at birth) and nidifugous which means they are covered in down and capable of locomotion, leaving the nest soon after hatching (Lord 1997, 16). Dotterel are relatively tame, yet they will call and alert when the presence of an intruder is noted. A perceived threat will cause adults to leave nests and commonly produce a skilled repertoire of distraction techniques (Lord 2001, 16).

The most recent recovery plan for the species (Dowding and Davis 2007, 8) identifies that predation, mainly of eggs and chicks, is the major threat to the northern subspecies. Disturbance is considered a further main threat and during breeding is indicated in lower productivity and at the chick raising stage in reduced fledgling success (Dowding and Murphy 2001, 53 Lord 1997, 18, Lord 2001, 237).

The majority of dotterel are found on the east coast of New Zealand, an area experiencing significant coastal development intensification (Dowding and Davis 2007, 15). Several key breeding sites (Dowding and Moore 2006, 82) are located in areas of high recreational demand regularlyexposing populations to the presence of humans. Moreover, breeding sites of single pairs can be found sporadically along coastal beaches, in areas heavily frequented by holidaymakers in the busy summer breeding season. The recovery plan identifies that "in the medium to long term the cumulative impact on a few pairs at many sites will inevitably have an adverse effect on the taxon as a whole, by reducing numbers and range" (Dowding and Davis 2007, 15). Where inadequately managed, activities involving vehicles, dogs, stock and water craft have impacted negatively with nests particularly vulnerable to destruction. Further studies are required to better understand the nature and extent of the problem. 
In these circumstances delivering effective habitat protection is complicated by the thin and wide distribution, the permeable nature of the coastal strip and the pervasive presence of humans and their trappings. Fixed refuges which exclude humans are beneficial, yet difficult to advocate for in areas of high social recreational value and where nest sites and foraging areas may be ephemeral in nature. Where the viability of wildlife is threatened, beach closures at various temporal and spatial scales are known to successfully protect wildlife and may be required where coexistence cannot be effectively secured (Weston et al. 2014, 1003).

Vulnerable nest sites on open beaches and coastal fringes are commonly roped off in the New Zealand example by local volunteers with support from industry and government agencies. The ropes protect eggs and incubating birds from much of the foot traffic, yet can do little for precocial chicks which must forage at the water's edge from birth. Unless the roped off areas are very large they will not prevent the birds' alert responses which commonly see adults leave the nest, expending energy and rendering nests exposed to predation by other birds such as oyster catchers and gulls. Furthermore, Ranger reports document compliance issues, and whilst the presence of a ranger reduces such issues it does not eliminate them (Dowding 2010, 7).

Regulating approach distance- mobile habitat protection/extended species protection

An increasing number of studies has been undertaken to understand the phenomenon of disturbance, its causes, effects and factors that may mediate disturbance responses. From this research Weston et al. $(2012,269)$ report:

One of the most consistent findings of disturbance research is that the response of birds is inversely related to the distance between the bird and the stimulus. The distance at which a behavioural escape response occurs is known as the FID [Flight-initiation distance] (Stankowich and Blumstein 2005), a concept apparently first described by Hediger (1934). 
Additional and related measurements identified in literature include the alarm-initiation distance, detection distance and the physiological-initiation distance each which indicates a response measured in relation to distance (Weston 2012, 270). The measures provide a rule of thumb (often species-specific) that can govern fixed habitat protection site size and design, and permissible approach distance for buffer zones or setbacks (Schlacher, Weston et al. 2013). Looking beyond fixed habitat protection, and given the problem of threatened species mobility in unprotected areas, the utility of FIDs as either an adjunct of species protection or as a form of mobile habitat protection requires consideration.

The regulation of approach distances for marine mammals is not uncommon and similar measures could be applied to other threatened species in the New Zealand environment. Obstacles at law, particularly in terms ofenforcement present, yet as interactions between people and threatened species intensify, new approaches require consideration. Not entirely fanciful, a New Zealand local government agency has recently considered give way rules on beaches to apply to horses and other vehicle when in the presence of small animals such as nesting birds (Mitchell 2015). In addition, greater education of stakeholders is required to understand not only the need to avoid the disturbance of species, but also how to achieve this. For instance, Australian research shows that although beach users understood the need to avoid nests they were surprised that precocial chicks had to feed themselves at hatching and required access to the water's edge, thus not fully understanding how to change recreational activities to avoid adverse impacts (Maguire 2015, 74).

In summary, large scale habitat protection/and or beach closures can significantly reduce disturbance effects. Complementing this protection with flexible responses related to approach distances may manage social expectations, yet provide reduction in pressure from disturbance. A Regional Coastal Plan, prepared under s 57 of the RMA could readily invoke such a mechanism through development of rules limiting approach distances to threatened species. Such rules could be subject to spatial, temporal or species-specifics consideration identified through maps/overlays or schedules or a combination of these. Justification for any 
such provision would be located in evidence of disturbance, the requirement of s 5 RMA to promote sustainable management of natural resources, together with the need to recognise and provide for the natural character of the coastal environment (s 6(a)) and the significant habitats of indigenous species (s 6(c)), and the requirements of policy 11 of the NZCPS.

\section{Conservation planning and development controls- strategic and operational}

The opportunity to manage species disturbance arises both at the operational and the strategic level, and protection of the coastal environment and the habitats of indigenous species is mandated by the RMA as discussed, and further clarified and strengthened by the NZCPS, in particular policies 6, 7,11 and 13 .

At the operational level, the segregation of incompatible activities applied through spatial zoning plans and tied to permitting regimes may limit disturbance, particularly where species habitat is fixed. Permitting regimes tend to operate on a case by case basis and species disturbance is not a problem readily reconciled on this basis for several reasons. The first is due to the difficulty of capturing cumulative and synergistic effects and the second is the lack of species specific data and limited consenting time frame for preparing thorough species assessments which contemplate inter-generational effects (Wallace, 2014, 386). The impacts of disturbance on the New Zealand dotterel have been considered in case law. Potential disturbance threats to dotterel have been traversed in various hearings: campgrounds in the Coromandel and in Northland, the establishment of wind farms on the west coast, subdivision in the Rodney District, Aotea Great Barrier Island, Coromandel, Kawhia Harbour, and Waikanae, marinas in Coromandel, and sand extraction in Rodney and the Bay of Plenty, (Wallace 2014, 123). It is uncommon for consents to be declined due to disturbance effects, and a central problem is quantification of effect. Where, for example, dotterel populations are thinly and widely spread, isolated impacts are difficult to quantify and assess in both the immediate and wider context, particularly where research in the locale and related to the species is lacking. The problem is described by Judge Newhook in the context of mangrove clearance at Mangawhai (Mangawhai Harbour Restoration Society Inc v Northland Regional Council [2012] NZEnvC 232: 
[83] We have no doubt that human disturbance of birds feeding, roosting and nesting within the estuary, on the harbour fringes and on the sandspit, is of serious concern. The evidence is clear that such disturbance is occurring, and we find that it would increase as a result of this proposal, even though we do not have a quantitative measure of the effects at any given population level. The displacement of birds from other more popular (for recreation) coastal areas constitutes quite compelling evidence of the seriousness of that effect.

In Tairua Marine Ltd v Waikato Regional Council Environment Court Auckland, A108/05 1 July 2005, Judge Sheppard held: "We accept that the loss of significant habitat of indigenous birds is cumulative on losses of their habitat elsewhere within their range." It is difficult to quantify and/or obtain a strategic view of the disturbance impacts of people and development upon threatened species habitat when presented with single applications, particularly where inducement for consent consists of a range of mitigation measures/offsets as opposed to a requirement for avoidance of the effects. Disturbance of species by intensifying human activity in New Zealand currently ranks lower than the significant threat of invasive mammalian predators and thus mitigation packages offering predator control are persuasive and beneficial, but may serve to limit closer scrutiny of the impacts of cumulative development on threatened species. Quantification of cumulative effects is further constrained by high levels of human activity in coastal locations currently not captured by regulatory schemes in public coastal space.

Significant opportunity yet exists in New Zealand to develop mechanisms which better consolidate development and capture under regulated human activity to the benefit of threatened and sensitive species through more. Related to this is the need to develop a more consistent and comprehensive conservation planning mechanism for threatened species. In particular, strategic planning tools which integrate across the private and public estates, and focus upon species conservation status, as opposed to place, are lacking in the New Zealand example (Wallace 2016, 15).Harnessing the potential of strategic conservationplanning requires a stronger understanding of the limits and benefits of coexistence, the distribution ofthreatened species, the consequences of human activity to 
particular populations and species, and how the problem is compounded by factors such as ecological complexity, synergistic and cumulative impacts of threats.

\section{Conclusion}

Disturbance of coastal species is a problem which is expected to intensify, and regulatory responses and tools are needed to better manage the threat. Reducing disturbance effects to species may enhance resilience to intractable threats such as climate change. For threatened species in New Zealand, species protection from disturbance under the Wildlife Act 1953 is constrained through lack of a standalone offence for species disturbance, lack of clarity as to the meaning of disturbance including judicial interpretation limiting consideration of temporary displacement of wildlife, lack of integration between wildlife offences and planning mechanisms, lack of knowledge and implementation deficits.

To drive recognition of disturbance and strengthen species protection, an offence of disturbance, independent of hunting and killing, as seen with European counterparts is required. The beneficial effect of such a measure turns upon definition of disturbance and associated thresholds of harm. Measuring thresholds of harm to species in constituting disturbance requires species-specific assessments which examine the intensity, duration and frequency of repetition of disturbances, direct and indirect negative effects, particular sensitivities of species including important life cycle stages, and the significance of the effect on the conservation status of the species. Species rarity and conservation status are of note in the New Zealand example where numbers of threatened coastal species are very high, suggesting that lower levels of disturbance may create greater harm than in areas where threat levels are not as elevated. Exempting disturbance to threatened species in the general environment on the grounds of lack of intention may be sensible in limited circumstances, however, where the presence of threatened species and the risk of harm from disturbance is communicated to the public, the known vulnerability of the species should limit 
any defence. Revision of the law to enact a standalone offence for disturbance of threatened species is required to strengthen the current position.

Habitat protection for threatened species in coastal margins is compromised by thin and wide distribution of species, species mobility, and the permeable nature of the coastal strip and the pervasive presence of humans. Developing mobile habitat protection or strengthened species protection through the use of "approach distances" in coastal plans/regulations, such as RMA Regional Coastal Plans, may limit disturbance effects, although are unlikely to be as effective as beach closures. Regulatory controls and permitting schemes directed towards managing adverse effects to species from human use and development are constrained in the management of disturbance effects due to ad hoc approaches, associated cumulative effects and insufficient species data. Greater research and planning efforts in this regards are required. In addition, strategic planning tools which integrate across the private and public estates, and focus upon species conservation status, as opposed to place, are lacking in the New Zealand example.

Blumstein D, Anthony L, Harcourt R, and Ross G, (2003). Testing a key assumption of wildlife buffer zones: is flight initiation distance a species-specific trait? Biological Conservation 110(1), 97-100. 
Collins D (2013). Gentrification or 'multiplication of the suburbs'? Residential development in New Zealand's coastal countryside. Environment and Planning A45(1), 109-125.

Controller and Auditor General (2006). Department of Conservation: Planning for and managing publicly owned land(report).Audit Office.

Craig J, Anderson S, Clout M, et al. (2000). Conservation issues in New Zealand. Annual Review of Ecology and Systematics, 61-78.

Davenport J, and Davenport J,(2006). The impact of tourism and personal leisure transport on coastal environments: a review. Estuarine, Coastal and Shelf Science67(1), 280-292.

Department of Conservation (2011). Gazetted Wilderness Areas - some key Questions Department of Conservation.

Defeo O, McLachlan A, Schoeman DS, et al. (2009). Threats to sandy beach ecosystems: a review. Estuarine, Coastal and Shelf Science81(1), 1-12.

Dowding J (2010). Potential impacts on endemic shorebirds of the operation of a private campground at Wahitapu lane, Opoutere beach (report). Opoutere Ratepayers \& Residents Association, Inc.

Dowding J and Moore S (2006). Habitat networks of indigenous shorebirds in New Zealand(report). Department of Conservation.

Dowding J (2013). New Zealand Dotterel. In Miskelly C editor, New Zealand Birds Online. Available at: http://www.nzbirdsonline.org.nz(cited 10 Oct 2015).

Dowding J and Davis A (2007). New Zealand Dotterel (CharadriusObscurus) Recovery Plan, 2004-14(report). Department of Conservation.

Dowding J and Murphy E (2001). The impact of predation by introduced mammals on endemic shorebirds in New Zealand: A conservation perspective. Biological Conservation 99(1), 47-64. 
Environment Directorate General of the European Commission (2007). Guidance Document on the Strict Protection of Animal Species of Community Interest under the Habitats Directive 92/43/EEC (2007).

Fox A and Madsen J (1997). Behavioural and distributional effects of hunting disturbance on waterbirds in Europe: Implications for refuge design. Journal of Applied Ecology, 1-13.

Gill J (2007). Approaches to measuring the effects of human disturbance on birds. Ibis 149, 914.

Glover H, Weston M, Maguire G, Miller K and Christie B (2011). Towards ecologically meaningful and socially acceptable buffers: Response distances of shorebirds in Victoria, Australia, to human disturbance. Landscape and Urban Planning 103(3), 326-334.

Hitchmough, R (2013). Summary of Changes to the Conservation Status of Taxa in the 200811 New Zealand Threat Classification System Listing Cycle(report). Department of Conservation.

Koch S and Paton P (2014). Assessing anthropogenic disturbances to develop buffer zones for shorebirds using a stopover site. The Journal of Wildlife Management78(1), 58-67.

Lausche B and Burhenne-Guilmin F (2011). Guidelines for Protected Areas Legislation (report). IUCN.

Liley D and Sutherland W (2007). Predicting the population consequences of human disturbance for ringed plovers Charadrius hiaticula: A game theory approach. Ibis149, 82-94. Lord A, Waas J and Innes J (1997). Effects of human activity on the behaviour of Northern New Zealand dotterel Charadrius obscurus aquilonius chicks. Biological Conservation 82(1), 15-20. Lord A, Waas J, Innes J and Whittingham M (2001). Effects of human approaches to nests of Northern New Zealand dotterels. Biological Conservation 98(2), 233-240. 
Maguire G, Miller K, Weston M and Young K (2011). Being beside the seaside: Beach use and preferences among coastal residents of South-Eastern Australia. Ocean \& Coastal Management 54(10), 781-788.

Makgill R and Rennie H (2012). A model for integrated coastal management legislation: A principled analysis of New Zealand's Resource Management Act 1991 The International Journal of Marine and Coastal Law 27, 135-165.

Martín B, Delgado S, Cruz A, Tirado S and Ferrer M (2015). Effects of human presence on the long-term trends of migrant and resident shorebirds: Evidence of local population declines. Animal Conservation 18(1), 73-81.

Ministry for the Environment (2007). Protecting our Places: Information about the Statement of National Priorities for Protecting Rare and Threatened Native Biodiversity on Private Land(report). Ministry for the Environment.

Miskelly C, Dowding J and Elliott Get al. (2008). Conservation status of New Zealand Birds, 2008. Notornis 55,117-135.

Mitchell C (2015). Bylaw 'an insult to the human race'. Available at http://www.stuff.co.nz/the-press/news/north-canterbury/68281700/Bylaw-an-insult-onthe-human-race (cited 10 Oct 2015).

Navedo J and Herrera A (2012). Effects of recreational disturbance on tidal wetlands: supporting the importance of undisturbed roosting sites for waterbird conservation. Journal of Coastal Conservation 16(3), 373-381.

Schlacher T, Weston M, Lynn D and Connolly R (2013). Setback distances as a conservation tool in wildlife-human interactions: Testing their efficacy for birds affected by vehicles on open-coast sandy beaches. PloS one 8(9), e71200.

Schlacher T, Nielsen T and Weston M (2013).Human recreation alters behaviour profiles of non-breeding birds on open-coast sandy shores. Estuarine, Coastal and Shelf Science118, 3142. 
Tarr N, Simons T and Pollock K (2010). An experimental assessment of vehicle disturbance effects on migratory shorebirds. The Journal of Wildlife Management74(8), 1776-1783.

Taylor G, Marsden, I and Hart D, 2013: Management of sand beaches for the protection of shellfish resources(report). University of Canterbury, Estuarine Research Report 41.

Van der Zande A and Verstrael T (1985). Impacts of outdoor recreation upon nest-site choice and breeding success of the Kestrel. Ardea 73, 90-99.

Wallace P and Fluker S in press (2016). Protection of threatened species in New Zealand New Zealand Journal of Environmental Law.

Wallace P (2014). Boundaries of Absolute Protection: Distribution of Benefit and Harm to Birds through Law and Planning in New Zealand. PhD thesis, University of Waikato.

Wallace P (2015). The reduced effect of International Conservation Agreements: A New Zealand case study. Journal of Environmental Law27(3), 489-516.

Weston M, McLeod E, Blumstein D and Guay P (2012). A review of flight-initiation distances and their application to managing disturbance to Australian birds.Emu, 269-286.

Weston M, Schlacher T and Lynn D (2014). Pro-environmental beach driving is uncommon and ineffective in reducing disturbance to beach-dwelling birds.Environmental Management 53(5), 999-1004.

Whitfield D and Rae R (2014). Human disturbance of breeding Wood Sandpipers Tringa glareola: Implications for "alert distances" in prescribing protective buffer zones. Ornis Fennica 91(2), 57.

Wilson K-J (2004). Flight of the Huia: Ecology and conservation of New Zealand's frogs, reptiles, birds and mammals, Canterbury University Press, Christchurch.

Woodley, K (2012). Shorebirds of New Zealand; Sharing the margins, Penguin Books (NZ) Ltd, New Zealand. 